\title{
A Multidimensional Perspective Study of the English Language
}

\author{
Hui Zhang \\ School of Foreign Languages Sichuan Technology and Business University \\ Meishan Sichuan 620036
}

\begin{abstract}
Keywords: the English language ; multidimensional perspective ; politics ; culture
\end{abstract}
\begin{abstract}
English not only is the most widely circulated language, but also the global language in the world. Therefore, the study of the English language is enduring. However, most of the past studies focused on the language itself, such as the language's pronunciation, vocabulary, syntax, semantics and so on. The studies have emphasized the communicative function of English as an international language, neglecting other influencing factors of language application, hence, the studies in the past somehow lack multidimensional research. Language is not an isolated existence, but is closely related to other disciplines. Therefore, in the study of the English language, integrating with other disciplines to develop further research on English becomes necessary. Without doubt, multidimensional research perspective to comprehensively analyze and sort out the different meanings of the English language is made the research issue.
\end{abstract}

\section{Introduction}

Language is used to express and interpret meanings, without its function as the bridge and externalization, a country's civilization will not be able to completely be interpreted . Language is the symbol of one nation, to some extent, it can also be called the most advanced science in a country . English as, the most widely used language in the world, whose connotation and value are quite important . However, at present, the research on English mainly projects the ontological study and regards it as a pure language. In fact, English as a language is bound to other disciplines. In the process of studying the English language, multidimensional perspective such as the perspective of politics, culture and philosophy can not only help to understand the English language comprehensively, but also help to extend the connotative value of the English language.

\section{Significance of the Study from multidimensional Perspectives}

As a common language in the world, English is widely used and plays an important role in intercultural communication and cooperation. Although in recent years, the upsurge of business English has promoted the research into a field, and the scope of the search has opened a new page, the study is not confined to the limited purview, however, the progress hasn't changed the current focus which is based on the language's basic meanings as well as its functions. The interdisciplinary research hasn't attracted enough attention, so has the integration of academic perspective. Based on the reality, it is of great value to inspect and investigate the English language from multidimensional perspective.

\subsection{Requirement of the Research Limitation}

With the frequent international trade, the prosperous international economic, cultural, political exchange and cooperation, the international role of English is becoming more prominent. But in sharp contrast, the study of the English language is relatively lagging behind, which still focuses on its basic contents and functions it conducts, which leads to some of the research contents based on the traditional concept that is called "fried rice". Yet, The role of the current English has clearly gone beyond its basic content, and it goes toward the integration of disciplines. It is obvious that the lack of innovative thought into deep cultivation of the connotative value leads to the low level of the research. Therefore, the research on the English language in depth is necessary and the integration with other courses seems to protrude. Only when the research is truly combined with the 
practice of life can the scientific and objective analysis be carried out. Hence, just from the multidimensional perspective, the value of the English language is really highlighted and the integration of the different disciplines can be realized.

\subsection{Requirement of the Creation of New Words}

The multidimensional perspective of English language is not a castle in the air , but based on a broad social basis. It is reasonable to adopt a multidimensional perspective to look into the English language from the new creative vocabulary as well as the words coming from literal translation, due to a wide range of social basis. At present, the status of China in the international community is more and more important which makes the image as a big country is further determined. The exchange between China and other countries becomes extremely prosperous and the international competition becomes unexpectedly fierce. Under such circumstance, the domestic talents have stepped out of the country and have integrated into the world. At the same time, other countries in the world has paid more attention to the prosperity and development of China's market. Such delicate phenomenon between countries makes some interesting "literal-translation language" gradually become a popular language. The hot phenomenon can be dated back to the early time as Chinese Kungfu star, Bruce Lee gained the sense of identity acceptance and made Chinese Kungfu pursued by the people worldwide. Nowadays, with the wide spread of the internet, hot net language has narrowed the distance between China and other countries, making the English language and the Chinese language achieve a very good fusion, thus the so-called Chinese-style English, Chinglish is appearing. There is no doubt that the study of the English language from multidimensional perspective can not only promote the creation of new vocabulary which is up to date, but also to expand the cultural interaction as well as to propel the new development to some extent.

\subsection{Requirement of the Times' Development}

In today's times, the world that people face every day is enduring drastic changes. Due to the rapid development of the times, the communication between people is increasingly frequently and deepening. Faced with the new situation, people become dissatisfied with the existing hysteretic culture and civilization, expecting the upsurge of new ones to meet the new age's development, which is in line with the new characteristics. The mark in the new era is undoubtedly expressed in the language that is popular in the world in a unique way.

In today's era, People need to continue to learn new knowledge in order to achieve further progress as well as not to be obsoleted by the times, which indicates that any individual can not stand still and keep wandering. Single perspective no longer adapts to the new epoch, so a more comprehensive, integrative and interdisciplinary trend becomes necessary in order to cater for the survival and development of the new changes. As an important communicative channel, English primary role is to meet the specific needs of the people. It is easy to see that with the development and progress of the times, English shouldn't be regarded as a pure language, for it is gradually penetrating into various disciplines, which promotes the formation of the research from multidimensional perspectives. Although there's still some room that needs refining, the multidimensional research scope gradually becomes a significant aspect to push the English language forward.

\section{Exploration on English from the Multidimensional Perspective}

English is the popular language in the world, which determines the necessity of conducting a comprehensive and thorough study of its function. Hence the every avenue of research is being pursued, which can promote the development of the English language scientifically and comprehensively. The research also makes the English language and people's real life become closer, meanwhile, it makes the practical force of English become outstanding. Therefore, the study on the English language from multidimensional perspectives can be attempted to begin with the following aspects . 


\subsection{Study from the Perspective of Culture}

Language is an external form of culture and deeply rooted in culture, which not only has a strong cultural attributes, but also has a strong cultural difference, so there's a natural difference between languages. For example, China is one of the world's largest country with a large number of dialects. It is not astonishing that there exists great difference between two adjacent areas or just across a small mountain, no matter the form or the performance is considered.

The same principle is applied to the English language, therefore one important dimension to study English is from the cultural perspective. The first step of the scientific study on the culture of the English language is to understand the typical cultural properties of English-speaking countries, for example, the inverted sentence is widely used in British English due to their special cultural characteristics. When the English language is analyzed, just regarding the external forms as the basis is somehow equal to the castle in the air. It is difficult to analyze and comprehend the core cultural value of English completely. Based on this, studying the English language must be rooted in culture. Only when the unique characteristic of culture is taken into consideration can human language be analyzed and comprehended deeply, which originates from the fact that language as an external form of culture, has the feature of typical cultural exclusion. For instance, every language carries language taboo for its distinctive culture, so does English. It is obvious that in the research on English cultural aspect is a must.

\subsection{Study from the Perspective of Philosophy}

Linguistics and philosophy are closely related. Thus in the process of study, the philosophical perspective to examine and recognize the English language is the basis, quite a lot of the characteristics of the English language from the depth of philosophy should be analyzed and understood. This is mainly because the English language as an important communicative medium, is naturally bound to the ideological world. In fact, the communication is the transmission of people's view of world in essence. At the same time, speakers' language habit has a very close relation to the philosophical perspective of linguistics. Therefore, from the philosophical perspective to study linguistics can not only widen and deepen the understanding of language itself, but also can provide adequate nutrition to deepen the study of philosophy.

Based on this, it is necessary to expound and recognize the English language comprehensively through maintaining the close relationship between language and philosophy as well as from the foundation of the philosophical system. Logically, philosophical dimension has become an indispensible part in the research on the English language.

\subsection{Study from the Perspective of Politics}

Any language exists in a special social environment and bears a deep political imprint. Politics serves as an invisible hand to regulate the use of language. People's life can't move on without politics. Hence, language plays the role of guidance to some extent. In order to avoid conflicts in certain circumstance, the language which is related to politics seems to take the trend of vagueness. For example, in some cases, definite judgments can't be given out directly, which leads to the use of rhetorical devices, especially the use of metaphor. English as the the world' s widely used language has no exception, which determines its unshakable position in the language research. To summarize, in order to fully understand English, there's an urgent need to take the political dimension into account.

\section{Conclusion}

English is a world language. In the process of English language research, the meaning and role should keep people's awareness. The relation between English and other disciplines should be understood scientifically and systematically. Therefore, a comprehensive review and analysis of the value of English from a multidimensional perspective appears vital important. Only in such a unique research way can the real function of English be highlighted. 


\section{References:}

[1] Cao Fengjing. On the multilingual perspective of English linguistics [J]. Journal of Shandong Youth Politics College, 2014 (2): 135-139.

[2] Zhang Min, thinking about the multilingual perspective of English linguistics research [J], Modern Communication, 2014 (09): 35-35. 